\title{
Evaluación federal del sistema de competencias de la Unión Europea: la interpretación de las políticas de apoyo y complemento
}

\author{
Miryam Rodríguez-Izquierdo Serrano \\ Profesora doctora de Derecho Constitucional \\ Universidad de Sevilla
}

Recibido: 16.03 .09

Aceptado: 04.05.09

\begin{abstract}
Resumen: Desde sus comienzos, el proceso de integración europea ha construido un espacio global de ejercicio del poder público donde Unión y Estados interactúan y donde cada uno tiene asignadas, o reservadas, distintas facultades de actuación sobre materias dadas. El funcionalismo como modelo explicativo de la integración ha permitido una interpretación expansiva de las competencias comunitarias, a pesar de los límites que establecen las cláusulas de atribución de los Tratados. Hay un grupo de competencias de la Unión configuradas como complementarias de las de los Estados, que es un buen referente para analizar tanto el efecto amplificador del funcionalismo, como la escasa virtualidad correctiva que consiguen ciertos principios federales, como primacía o subsidiariedad. Estos principios, sin embargo, podrían aportar un equilibrio diferente a la dinámica de las competencias, si en lugar de orientar la interpretación con una hermenéutica funcionalista, se hiciera con una hermenéutica adoptada, y adaptada, desde el federalismo para la Unión Europea.

Palabras clave: Unión Europea, competencias complementarias, subsidiariedad, primacía.

Abstract: Ever since the European integration process was started, a global space where public power is shared by the EU and the Member States has been built. Both, the Union and the States, act within their scopes of powers on subject matters either allocated to the EU or kept by the States. As an explanatory theory of integration, functionalism has allowed an extensive interpretation of Community competences, disregarding the limits set by the EC Treaty in its conferral clauses. There is a group of competences of the Union described as supplementary or complementary to those of the Member States', which is a good referent to analyse the amplificatory effects of functionalism, as well as to show how functionalism also influences federal principles, such as primacy and subsidiarity, making them unable to correct those effects. Both principles, notwithstanding, could offer a different balance just in case a federal hermeneutics, which should be specifically thought for the EU, were applied to the interpretation of competences, instead of making use of functionalism as hermeneutics.
\end{abstract}

Key words: European Union, complementary competencies, subsidiarity, primacy.

Sumario: Introducción.-I. La cuestión de las competencias en la experiencia federal y en la Europa de la Unión. 1.1. Legado federal y plu- 
ralismo constitucional europeo. 1.2. Competencia y controversia en la experiencia federal.-II. Competencias de la Unión, competencias estatales y razones para el conflicto. 2.1. Constitucionalismo o funcionalismo: primeros desajustes para la interpretación. 2.2. La ordenación de las competencias de los Tratados.-III. Las competencias complementarias y su interpretación. 3.1. Identificación y caracterización de las competencias complementarias. 3.2. Modelo de interpretación funcionalista. 3.2.1. Efecto en la interpretación institucional y subsidiariedad. 3.2.2. Efecto en la interpretación jurisprudencial y subsidiariedad. 3.2.3. Efecto en la interpretación jurisprudencial y primacía.-IV. Condiciones o principios para una interpretación federal.-V. Conclusión.

\section{Introducción}

El análisis de la Unión Europea desde el Derecho Constitucional requiere casi siempre una especial atención metodológica. La condición previa a cualquier intento explicativo de la configuración normativa y de los límites de ejercicio del poder público en el espacio europeo es enfocar bien, estableciendo el marco conceptual en función del cual se va a trabajar. Esa exigencia se manifiesta para todos los posibles objetos de estudio singulares: instituciones, sistema de fuentes, reforma de los Tratados, procesos de decisión, derechos fundamentales o relaciones entre ordenamientos. Dentro de ese último campo de las relaciones entre ordenamientos, el sistema de reparto de competencias plantea cuestiones interesantes cuando se explica a través de una precomprensión federal del orden formado por la Unión y los Estados miembros. El uso de categorías del federalismo pone de relieve que la manera en la que las competencias son ejercidas por los actores institucionales europeos tiene unas consecuencias determinadas sobre las posibilidades de actuación estatal.

En este trabajo vamos a realizar una aproximación panorámica a esos problemas, tomando como muestra las competencias complementarias de la Unión y observando algunas de las pautas de su ejercicio. En concreto, la reflexión sobre las peculiaridades en la configuración y en la interpretación de esas competencias complementarias ofrece un cuadro explicativo que muestra varios puntos de interés. Muestra las contradicciones que se producen entre configuración e interpretación. Revela el porqué de esas contradicciones. Y, por último, evidencia los efectos de tales contradicciones sobre la relación entre los órdenes constitucionales de la Unión y de los Estados. En última instancia, esa panorámica puede utilizarse como plataforma desde la que sugerir elementos de corrección. Hay principios normativos, como la primacía y la subsidiariedad, que, desde la interpretación, son capaces de dar pautas que minimicen las contradicciones y los efectos disfuncionales para la comprensión del orden global formado por Unión y Estados. Un orden global que abordamos desde el constitucionalismo y analizamos conforme a categorías propias del federalismo. 


\section{La cuestión de las competencias en la experiencia federal y en la Euro- pa de la Unión}

La forja del orden federal de los Estados Unidos fue en su tiempo una inspiración para las revoluciones liberales a ambos lados del Atlántico. Por primera vez se rompía con el orden monárquico del Antiguo Régimen. Por primera vez se instauraba un sistema político a partir de una Constitución elaborada por los representantes de los distintos territorios ex coloniales. Esa conjunción de novedades también convirtió al modelo americano en referente para el desarrollo, bastante posterior, del constitucionalismo democrático en Europa. E igualmente consagró al federalismo como ideal de organización de estructuras estatales territorial y políticamente plurales. La Constitución Federal, corriendo el tiempo, se ha consagrado como una categoría normativa específica dentro de la disciplina del Derecho Constitucional.

La interpretación y la aplicación singular de las normas de la Constitución de 1787, por su parte, han ido acumulando todo un legado de experiencia federal que, en su adecuada medida, puede ser aprovechado por ese constitucionalismo pluralista, fragmentado, inédito y obtuso que se predica de la Unión Europea. Es un constitucionalismo fragmentado puesto que reparte sus fundamentos, como mínimo, entre Tratados de integración y normas constitucionales de incorporación al complejo europeo y de recepción de sus actos. Es inédito, siguiendo a Cruz Villalón, porque el orden formado por la Unión y los Estados miembros se despliega en «una pluralidad constitucional sin precedentes», que abandona el terreno de las organizaciones internacionales, sin por ello asimilarse al modelo de pluralidad federal del Estado constitucional. Y es obtuso porque, aun al trasladar las categorías del Estado constitucional al conjunto de Unión, Tratados, Constituciones y Estados miembros, el resultado sigue requiriendo una denominación constitucional singular, especial, que a su vez necesita explicarse de nuevo ${ }^{1}$.

${ }^{1}$ P. CRuz Villalón, La Constitución inédita, Trotta, Madrid, 2004, p. 137. Lo cierto es que el término más utilizado para la descripción de la dimensión interrelacional del pluralismo constitucional europeo es el de multinivel, tomado de la elaboración teórica de I. Pernice. I. Pernice, «Multilevel constitutionalism and the Treaty of Amsterdam: European Constitution-making revisited?», Common Market Law Review, num. 36, 1999, pp. 703750; o I. PERnice y F. MAYER, «De la constitution composée de l'Europe», Revue Trimestrièlle de Droit Européen, 36 (4), 2000, pp. 623-647. Sin embargo, otros autores sugieren que el uso del término multinivel no es del todo apropiado para un sistema que quiere desvincularse de la jerarquía como criterio de organización interna. P. HÄBERLE, ¿Tienen España y Europa una Constitución?, Fundación El Monte, Sevilla, 2004, p. 96. El término de constitucionalismo entrelazado (intercciamento costituzionale) es de J. ZILLER, «La función de los conceptos constitucionales de los Estados miembros en la nueva constitución para Europa», en M. Cartabia, B. DE WitTe y P. Pérez Tremps (dirs.), Constitución Europea y constituciones nacionales, Tirant lo Blanch, Valencia, 2005, pp. 27-85, en concreto p. 85. 


\subsection{Legado federal y pluralismo constitucional europeo}

Cuando se habla de constitucionalismo de la Unión Europea, se hace alusión al esfuerzo teórico mediante el cual la doctrina constitucional, desde los años noventa del siglo Xx hasta nuestros días, quiere facilitar a la integración europea un marco de explicación fundamentado en las bases sustantivas propias del constitucionalismo. Enumeradas de forma apresurada y escueta, esas bases serían democracia, imperio de la ley, garantía de derechos y división de poderes. Ese esfuerzo, como ya se ha apuntado, parte de una realidad jurídica que no es formalmente constitucional, sino que está compuesta por los Tratados europeos y las Constituciones estatales. Esos son los basamentos textuales de un conglomerado normativo sobre el que, con mayor o menor acierto, ha de apoyarse la legitimidad de una realidad que sí que tiene dimensión constitucional, y que consiste en que las instituciones supranacionales de la Unión ejercen importantes competencias y crean normas jurídicas que son obligatorias en los Estados miembros de manera inmediata.

La vigencia de ese Derecho europeo se sitúa en su aplicación al mismo nivel que el propiamente estatal y convive con él. De manera que habrá cruces y superposiciones entre las regulaciones europeas y estatales, espacios de intersección material en los que tanto la Unión como los Estados tendrán competencias, y pretensiones de vigencia contradictorias que habrán de resolverse conforme a un sistema de solución común a ambos órdenes jurídicos. En consecuencia, es necesario que la coexistencia de distintos espacios públicos territorialmente ordenados, cada uno de los cuales asume una función diferente respecto al sujeto-ciudadano, esté sustentada en aquellos principios del constitucionalismo, y que el federalismo, como mecanismo de organización del pluralismo constitucional, sea un elemento que explique el marco constitucional común.

Si nos fijamos en las organizaciones federales, es fácil comprobar cómo la distribución de las tareas que debe llevar a cabo cada esfera de poder público -bien la Federación, bien los Estados- siempre ha sido un asunto en el que lo político ha precedido a lo normativo. Una vez establecidos constitucionalmente los mandatos de reparto de ámbitos de competencia, señalamiento de facultades y asignación de funciones, el factor político que condiciona una determinada organización de las competencias hace que las controversias en torno a ellas se resistan a conformarse con los márgenes

A tales críticas responde, entre otros, Mayer, alegando que los niveles no tienen por qué suponer, necesariamente, supraordenación, supervisión o subordinación, y que los niveles pueden entenderse como plataformas que en momentos están a la misma altura, y en otros a diferentes. F. C. MAYER, «The European Constitution and the Courts», en A. Von BoGDANDY y J. BAST, (eds.), Principles of European constitutional law, Oxford, Hart Publishing, 2006, pp. 281-333, en concreto pp. 320 y 321. 
determinados por las normas constitucionales de reparto. En cualquier caso, el optimismo racionalista llevó a los padres de la Constitución de 1787 al convencimiento de que era posible ordenar el sistema, darle un marco normativo y plasmarlo en un documento. Desde ese instante, el asunto de las competencias pasó a ser también un tema jurídico, un tema de la Constitución ${ }^{2}$.

A partir de entonces, lo político se mezcla con lo normativo cuando se estudia el asunto de las competencias, cuando se escruta la manera en la que son ejercidas en cada esfera, y cuando se intenta explicar el sentido en el que los actores institucionales de los diferentes espacios públicos -Federación o Estados- entienden e interpretan los mandatos constitucionales sobre ámbitos y límites de ejercicio de competencias. Pero al introducir la concepción democrática del orden federal, la cuestión de las competencias adquiere además una relevancia constitucional, y por tanto jurídica, mucho más fundamental. En efecto, el respeto a su configuración ya no es solo sensible desde el punto de vista de los poderes públicos o de las instituciones que las ejercen. La concepción democrática exige que la construcción jurídica de lo político se lleve a cabo exclusivamente desde, y hacia, el sistema de derechos $^{3}$. Por tanto, la dimensión constitucional de la cuestión competencial se enfoca ahora desde la perspectiva del sujeto y de sus derechos. Al incorporar tal perspectiva, se percibe cómo el respeto al reparto de competencias incide sobre la realización de los derechos de inclusión y de participación del sujeto en cada uno de los fora, espacios públicos, o comunidades políticas en los que se integra. Por este camino, y teniendo en cuenta que la cuestión de las competencias es determinante en la composición del sistema de fuentes, se hace visible que de su coherencia pende la posibilidad de que un individuo, ciudadano, sepa a qué atenerse cuando ejerce sus derechos de participación política. O cómo reaccionar cuando se le pretende aplicar tal o cual norma federal, antes que esta o esa otra del Estado federado correspondiente.

\subsection{Competencia y controversia en la experiencia federal}

De vuelta a la experiencia histórica y jurídica del federalismo, por la estadounidense sabemos que la ilusión del reparto, o de la separación de esferas, fue parcialmente defraudada por la necesidad de adoptar nuevas políticas ante los cambios estructurales del contexto económico y social. El desarrollo de las políticas intervencionistas del keynesianismo económico

${ }^{2}$ Es la reflexión que se hace Hamilton en A. Hamilton, «El federalista», XXXII, en A. Hamilton, J. Madison, y J. JAY, El federalista, México, Fondo de Cultura Económica, 2001.

${ }^{3}$ J. Habermas, Facticidad y validez, Trotta, Madrid, 1998, p. 156. 
fue el primer hito en esa ruptura del federalismo dual ${ }^{4}$. Hubo entonces que encontrar formas de dar lectura jurídica a la transformación de hecho de las relaciones entre los sistemas jurídicos, el federal y los de los Estados federados. El dualismo se convirtió a una nueva confesión, la del federalismo cooperativo. Al discurso tranquilizador de las esferas competenciales separadas, le sucedió el de las competencias compartidas y el de los mecanismos de colaboración ${ }^{5}$. Y, aun así, el marco de 1787 quedaba formalmente inalterado. Las normas constitucionales de distribución competencial seguían vigentes y eran límite y referencia tanto para los órganos políticos a la hora de ejercer las competencias respectivas, según su naturaleza federal o federada, como para los jueces y tribunales a la hora de situarse ante las leyes y cuestionar, o no, si respetaban el acuerdo inicial plasmado en la Constitución.

No sin conflicto, ese sistema de pluralismo ordinamental en el que la Constitución Federal tiene la última palabra ha pervivido y ha encontrado en cada momento reglas de adaptación que permitían lecturas conformes de las normas de reparto de competencias. La convivencia se ha conseguido mediante una conformación jerárquica de los ordenamientos jurídicos, independientes aunque relacionados y ordenados a causa de su vigencia bajo la supremacía federal. Esa supremacía que la Constitución del 1787 incluía en su Artículo VI y que podía interpretarse bien como supremacía constitucional, bien como primacía de la legislación de la Federación en su ámbito de competencia.

Pero la convivencia es algo muchísimo más difícil de organizar en un orden pluriconstitucional, como el de la Unión Europea, que no es piramidal sino policéntrico. Un orden, además, cuya razón de existencia es la atribución de competencias, la asignación de objetivos a un orden supranacional para realizar tareas que los Estados solo pueden realizar así: en conjunción con otros y organizados por una entidad neutral y aglutinadora. El sistema de competencias de la Unión Europea tiene un curioso árbol genealógico. En él se descubre la ascendencia directa del funcionalismo, principio inspirador de la creación de las Comunidades. Por otro lado, el sistema de la Unión tiene

${ }^{4}$ Schwartz, basándose en jurisprudencia del Tribunal Supremo de EE. UU., explica la progresión del federalismo americano y la erosión del federalismo dual inicial. B. SCHWARTZ, El federalismo norteamericano actual, Civitas, Madrid, 1984.

${ }^{5}$ García de Enterría considera que «hoy todos los federalismos y regionalismos en ejercicio han superado de manera definitiva la construcción de las autonomías sobre la técnica de la separación formal y absoluta de competencias entre el Estado y los entes miembros, la técnica de las "competencias exclusivas" parece entrar decididamente en el camino de las "competencias compartidas" o concurrentes», en E. GARCÍA DE ENTERRÍA, «Estudio Preliminar» en E. GARCíA DE ENTERRÍA (dir.), La distribución de las competencias económicas entre el poder central y las autonomías territoriales en el Derecho Comparado y en la Constitución española, Instituto de Estudios Económicos, Madrid, 1980, p. 24. 
una filiación adoptiva con el racionalismo: el funcionalismo y la comprensión constitucional del orden europeo por la doctrina constitucional y la jurisprudencia comunitaria delatan la pertenencia a esa progenie. La filiación biológica se establece generacionalmente con el pensamiento de la posmodernidad: fragmentación e integración dentro del contexto del orden global.

Este pequeño embrollo genético no pone las cosas tan fáciles ni al actor político, ni al abogado, ni al juez o tribunal de turno, ni, en nuestro caso, al analista. Y no solo por la falta de perspectiva histórica que permita ver de lejos la evolución del conjunto, sino porque estudiar el sistema competencial de la Unión parece haberse convertido en una auténtica partida de Tetris, en la que, una vez encajado un elemento, se ve caer desde la esquina superior derecha una pieza distinta que no se ajusta ni del derecho, ni del revés. Y aunque el atribulado constitucionalista se esfuerza en utilizar categorías del federalismo, convirtiéndolas primero al espacio europeo para poder pasar a la fase siguiente, explicando con resignación que la complejidad del tema hace compleja la explicación misma, las piezas que siguen apareciendo desde el cielo digital caen de cualquier manera. El Tribunal de Justicia sigue reconfortado por la tolerancia hacia la primacía. Y ciertos Tribunales Constitucionales estatales optan por no afrontar el problema: si lo ven de lejos, asumen que normalmente no habrá conflictos entre ejercicios de competencia estatal y europeos. Resuelven que si los hay igual ni se notan, y que si llegasen a notarse... entonces habría que ver ${ }^{6}$.

En definitiva, la naturaleza política de todo debate acerca de la distribución de competencias en la UE no libra al jurista de la necesidad de poner orden en los referentes. Principalmente porque tal orden repercute en el sistema de fuentes que debe manejar. Y, sobre todo, porque de ello depende la posibilidad de que el sujeto-ciudadano, nacional de Estado miembro, euroconsumidor, eurovotante y euroimplicado, pueda saber a qué atenerse a la hora de ejercer sus derechos políticos. $\mathrm{O}$ a la hora de presentarse ante un juez nacional pidiendo la aplicación o defendiendo la posición que las leyes, europeas y estatales, le otorgan.

Se trata de pasar a la segunda fase del Tetris de las competencias. Puede ser que, si se recolocan algunos de los elementos que se dan por sentados en la explicación habitual del reparto de tareas, encontremos sugerencias distintas a la de usar la primacía y olvidar el conflicto potencial. Para esa segunda fase, este escrito propone una partida con piezas nuevas. La propuesta es una

${ }^{6}$ Es la postura del Tribunal Constitucional español ante el Tratado que establece una Constitución para Europa. En su análisis del principio de primacía, que se incorporaba formalmente a través de ese Tratado, el TC consideraba que la separación de ámbitos de competencia de la Unión y de los Estados hacía poco probable el conflicto normativo. Declaración del Tribunal Constitucional, DTC 1/2004 de 13 de diciembre, suplemento BOE núm. 3 , de 4 de enero de 2005, FF. JJ. 3 y 4. 
aproximación al tema a través del análisis de un tipo concreto de competencias comunitarias: las complementarias. Seguramente es en este tipo de competencias donde más claramente pueden constatarse las disfunciones que provoca la falta de un marco apropiado, tanto teórico como normativo, para que la interpretación constitucional pueda situar cada una de las esferas políticas, Unión y Estados, en el sitio que le corresponde.

\section{Competencias de la Unión, competencias estatales y razones para el conflicto}

La definición normativa del sistema de competencias de la Unión Europea se encuentra, como en los órdenes federales al uso, en un documento único: los Tratados. Sin embargo, por lo dicho sabemos que el fundamento constitucional no se encuentra solo ahí. Está disperso en Tratados y Constituciones, en lugar de estar concentrado en un solo referente que aúne la voluntad constituyente de la ciudadanía y que establezca las reglas de convivencia de los diferentes espacios públicos. Los límites de actuación de Estados miembros y Unión en un sentido relacional no están unitariamente codificados en sus respectivas normas de cabecera. Cada uno ha de mirar respectivamente a la del otro para tener un referente completo sobre la corrección constitucional del ejercicio de las competencias. Dicho con otras palabras: la conformidad constitucional del ejercicio de las competencias tiene que residenciarse en los mismos elementos en los que lo hace la legitimidad del pluralismo constitucional europeo, que son las Constituciones nacionales y los Tratados constitucionalizados?

Además, desde el punto de vista normativo, la distribución de competencias en la Unión no es, en sí, ni una distribución ni un reparto. Lo que hay en los Tratados europeos es una atribución de competencias a las Comunidades, o a la Unión, para la consecución de unos fines específicos también consignados en esos Tratados. Toda otra competencia no atribuida, como ya deja dicho por dos veces el Tratado de Lisboa -artículo 4.1 y 5.2 TUE $(\mathrm{L})^{8}-$, se mantiene en la esfera de los Estados miembros. En lo que atañe a las Cons-

${ }^{7}$ Esas son las bases normativas de la Unión Constitucional de Ingolf Pernice, entendida como orden pluralista y construida como oposición a la conceptuación más propiamente estatista que hace Paul Kirchhof de Europa como Unión de Estados. I. PERNICE, Fondements de droit constitutionnel européen, <http://www.whi-berlin.de/>, 2002. P. КIRCHHOF, «The legal structure of the European Union as a Union of States» en A. Von BogdANDY y J. BAST, (eds.), Principles of European constitutional law, Oxford, Hart Publishing, 2006, pp. 765802.

${ }^{8} \mathrm{Al}$ estar pendiente de ratificación el Tratado de Lisboa, distinguiremos en las remisiones que se hagan a artículos del Tratado de la Unión cuando sea la versión de Niza (N) o la de Lisboa (L). El Tratado de Funcionamiento de la Unión aparecerá como TFUE y el clásico, el de la Comunidad Europea, como TCE. 
tituciones nacionales, en primer término, la atribución de competencias es posible gracias a la apertura de las normas fundamentales estatales a un orden jurídico distinto del que presiden. El ejercicio, desde lo estatal, del poder de integración constitucionalmente prefigurado, concretado en cláusulas de integración, posibilita una nueva conceptuación del Estado mismo, ahora integrado 9 . Como consecuencia de este proceso de atribución, los Estados limitan sus facultades de creación normativa en esos ámbitos de competencias atribuidos a las Comunidades y a la Unión.

En segunda instancia, la legitimidad constitucional de las competencias atribuidas en los Tratados europeos se sostiene en un doble fundamento: uno es esa apertura constitucional estatal y otro es la afirmación de autonomía constitucional del orden comunitario. La autonomía ha sido tramada en la construcción jurisprudencial del Tribunal de Justicia y luego consentida por la propia evolución del Derecho europeo ${ }^{10}$. Por otra parte, las competencias que las Comunidades han ido recibiendo no son, sin más precisiones, competencias que anteriormente ejercieran los Estados miembros en soledad y que ahora compartan en un espacio supranacional. La atribución forja unas competencias específicas que solo existen porque existe la Unión. No son concebibles la unión aduanera, el mercado interior, la política agrícola común o, inclusive, el euro sin la existencia de una organización supraestatal distinta de los Estados mismos. En el último caso, la adhesión sustituye alguna competencia estatal anterior, pero por lo común se superpone a las competencias persistentes de Estados y entes subestatales. Las competencias comunitarias no solo son distintas por el ámbito global en el que se ejercen, lo cual ocurre también con las competencias de la Federación en cualquier sistema federal. También lo son por la raíz funcionalista que engendró y estimuló la expansión de todo el sistema europeo desde los años cincuenta hasta hoy.

Como conclusión transitoria, se observa una primera dificultad para comprender el orden de competencias de la Unión por la manera en la que los referentes de constitucionalidad están configurados. El Derecho comuni-

\footnotetext{
${ }^{9}$ Esa apertura se traduce en una nueva conceptuación del Estado constitucional en Estado cooperativo y se concreta, para el caso de la UE, en programas europeos de las constituciones estatales. P. HÄBERLE, Pluralismo y Constitución, Tecnos, Madrid, 2002, pp. 124 y ss, y 256 y ss. Sobre el concepto de poder de integración y los límites de su ejercicio, A. LóPEZ CAstillo, Constitución e Integración, Madrid, Centro de Estudios Constitucionales, 1996. La nueva identificación del Estado como «integrado», en F. RUBIO LLORENTE, «El Constitucionalismo de los Estados Integrados de Europa», Revista Española de Derecho Constitucional, núm. 48, 1996, pp. 9-33.

${ }^{10} \mathrm{Al}$ respecto, J. H. H. WeILER, «La transformación de Europa» en J. H. H. WeILER, Europa, fin de siglo, Centro de Estudios Constitucionales, Madrid, 1995, pp. 13-126; K. J. ALTER, Establishing the Supremacy of European Law, Oxford University Press, OxfordNew York, 2001; o I. PernicE, Fondements de..., op. cit.
} 
tario derivado, producto del ejercicio de competencias de las Comunidades, encuentra su parámetro de validez y de constitucionalidad en un ordenamiento jurídico presidido por Tratados de integración y remitido en su fundamento a los órdenes constitucionales estatales. Mientras, la legislación estatal tiene su referente en la Constitución propia, la cual ha limitado las posibilidades de acción estatal a favor del complejo supranacional condensado por la Unión Europea. Las Constituciones estatales y los Tratados se sitúan como bisagras de un orden complejo que regula distintos sectores materiales de la realidad a través de diferentes sistemas de fuentes. El conflicto interordinamental aparece como efecto de esa realidad compleja en la que hay diferentes parámetros de constitucionalidad que fragmentan, a su vez, los sectores y ámbitos de competencia conforme a criterios distintos.

\subsection{Constitucionalismo, funcionalismo y primeros desajustes}

Abordemos en primer lugar los efectos que la diversidad de parámetros de constitucionalidad tiene sobre el asunto de las competencias en el sistema Unión-Estados. Insistiremos de nuevo en el método comparativo como instrumento de análisis, tomando modelos conceptuales del federalismo y trasladándolos al sistema de la Unión. Así se pueden evidenciar las diferencias que hay entre la concepción del problema de las competencias en un ideal, e idílico, orden federal estatal y la que hay en el orden pluriconstitucional europeo.

En un orden federal, el sentido de la Constitución es la convivencia, los derechos, y la organización y límite del ejercicio del poder público. Los principios de la Constitución federal son los que señalan los parámetros de constitucionalidad de todo el conjunto. Una Constitución federal puede privilegiar más o menos al ente federal, puede introducir más o menos mecanismos de contención, o de expansión, del poder central, pero en lo que al orden constitucional se refiere, los referentes que guían el ejercicio de competencias son iguales para todos, para la Federación y para los Estados miembros. En el Estado autonómico español, la realización democrática, el funcionamiento del Estado de Derecho, y los valores de libertad, pluralismo político, igualdad y justicia del artículo 1.1 de la Constitución, son los referentes del ordenamiento jurídico para el Estado y las Comunidades Autónomas. El mandato de promoción social del 9.2 se dirige a los poderes públicos, Estado, Comunidades Autónomas o Administraciones locales. Aun con el simplismo de esta ejemplificación, sirve para explicar que la concepción unitaria de los fines y valores del sistema constitucional hace que los conflictos que se dan como consecuencia de la distribución de competencias puedan ser resueltos conforme a ese mismo orden unitario. Y, por lo tanto, se resuelvan dentro del sistema mismo.

En la relación Unión-Estados miembros, sin embargo, los conflictos se tienen que resolver en una zona intermedia, una zona de intersección en la 
que hay una pugna solapada de sentido entre órdenes estatales y orden europeo. Las regulaciones del Derecho europeo están al servicio de los fines de la integración misma, definidos en los artículos 2 del TUE(N) y 2 TCE -ahora en el 3 TUE(L)-. Incluso a pesar de la incorporación de los valores constitucionales comunes de los Estados miembros como principios fundamentales de la Unión -artículo $6 \mathrm{TUE}(\mathrm{N}), 2 \mathrm{TUE}(\mathrm{L}){ }^{11}$, el fundamento de cualquier norma comunitaria siempre está en objetivos del Tratado y se apoya en una base jurídica concreta que, a su vez, describe un objetivo propio. La base jurídica por una parte relaciona la acción de la Unión con lo atribuido en el Tratado, y por otra señala a las instituciones el procedimiento concreto a seguir para la conformidad a Derecho del ejercicio competencial. Es en la primera de las dos significaciones en la que se descubre el sentido relacional de la base jurídica ${ }^{12}$. Delimita lo que la Unión puede hacer y, en consecuencia, dónde los Estados miembros han renunciado a hacer. Y señala, también, un objetivo al que orientar realizaciones en un determinado sector de la realidad: mercado, competencia, aduanas, libre circulación, moneda, pesca, política social...

El diseño del proyecto comunitario configura competencias finalistas que se orientan a la consecución de objetivos específicos. Con mayor o menor acuerdo, ese motor de impulso de la integración en la Europa comunitaria se ha identificado con el funcionalismo como método de integración. Su efecto, visto desde el prisma del pluralismo constitucional y de la interpretación de las normas de reparto, es que el ejercicio de competencias comunitarias puede entrar en contradicción con principios constitucionales

${ }^{11}$ De las cláusulas de interpretación y aplicación de la Carta de Derechos Fundamentales de la Unión, que fueron incorporadas en la versión que se incluyó en el Tratado Constitucional, se desprendía algo importante de cara a la interpretación de esos principios iusfundamentales, pues no parecía que los fines de la integración fueran a perder su hegemonía por lo que, en cierto sentido, se blindaba la interpretación de las competencias frente a la penetración de contenidos iusfundamentales. En efecto, el artículo II-111.2 del Tratado Constitucional afirmaba que «la presente Carta no amplía el ámbito de aplicación del Derecho de la Unión, ni crea ninguna competencia o misión nueva para la Unión, ni modifica las competencias y misiones definidas en las demás Partes de la Constitución». En la adhesión a la Carta que proclama el Tratado de Lisboa a través del artículo 6 del TUE(L) -y que le da el mismo valor jurídico que a los Tratados-, se repite esa idea. Se afirma que «las disposiciones de la Carta no ampliarán en modo alguno las competencias de la Unión tal y como se definen en los Tratados».

${ }^{12}$ Díez-Picazo explica que la base jurídica no solo se relaciona con el concepto de competencia de atribución, y por esa vía con la cuestión Unión-Estados. También, e incluso más fuertemente, la base jurídica es determinante en el equilibrio institucional de la Unión, ya que es la que indica el procedimiento de decisión que ha de seguirse en cada caso (unanimidad, mayoría, cooperación, codecisión...). L. M. DíEz-PicAzo, Constitucionalismo de la Unión Europea, Civitas, Madrid, 2002, pp. 173-187. 
estatales de distinta naturaleza ${ }^{13}$. Incluso puede provocar colisión entre normas de derecho derivado y normas constitucionales ${ }^{14}$. Por esta razón hay Tribunales constitucionales que recurrentemente llaman la atención sobre los límites que las Constituciones estatales marcan al ejercicio de las competencias comunitarias. En concreto, el juez constitucional alemán provocó una reacción favorable al compromiso con la defensa, e inclusión, de los derechos fundamentales en el parámetro de constitucionalidad material de la Unión ${ }^{15}$. Sin embargo esto no significa que la legislación conforme a objetivos y la técnica de apoyo en bases jurídicas se haya modificado.

El funcionalismo que informó el sentido del proyecto comunitario sigue influyendo en la configuración competencial y en el ejercicio de las competencias. Los espacios de conflicto no solo se crean a causa de la división de la realidad en sectores objeto de regulación, sino también a causa de la amplitud y potencial expansivo de las metas de la integración económica. Los fines de la integración impregnan todo tipo de competencias comunitarias. De manera que siempre que se elaboran normas europeas, los objetivos de los tratados orientan tal legislación. Solo tienen prioridad los límites constitucionales en la medida en que figuren en los propios Tratados, bien como objetivos, bien como límites propios ${ }^{16}$. Esto crea mayores problemas

13 Es delicado hablar del funcionalismo en este contexto, puesto que la naturaleza del concepto lo identifica como una teoría de integración, cuya adecuación para explicar el fenómeno de la europea es incluso debatida desde enfoques de Ciencia Política, en los que compite con otras como el intergubernamentalismo, el neoinstitucionalismo e incluso el federalismo. C. CLOSA MONTERO, «E pur si muove: teorías sobre la integración europea», Revista de Estudios Políticos, núm. 85, 1994, pp. 339-364. Sobre la manera en la que las instituciones comunitarias interpretan las competencias conforme a los fines de la integración, J. H. H. WEILER, «La transformación de Europa», op. cit.

${ }^{14}$ Ejemplos conocidos de este tipo de colisión están detrás de casos como el Asunto Internationale Handelgesellschaft, Sentencia del Tribunal de Justicia de las Comunidades Europeas de 17 de diciembre de 1970, C-11/70, ECR 1970, pp. 1125 y ss.; Asunto Comisión vs. Luxemburgo, Sentencia del Tribunal de Justicia de las Comunidades Europeas de 2 de julio de 1996, C 473/93, ECR 1996, pp. I-03207 y ss.; asunto Comisión vs. Grecia, Sentencia del Tribunal de Justicia de las Comunidades Europeas de 2 de julio de 1996, C 290/94, ECR, pp. I-03285; asunto Kreil, Sentencia del Tribunal de Justicia de las Comunidades Europeas de 11 de enero de 2000, C-285/98, ECR 2000, pp. I-69 y ss.

${ }^{15}$ Las famosas sentencias Solange I y II del Tribunal Constitucional Federal, BVergGE, de 29 de mayo de 1974 y 22 de octubre de 1986, ambas comentadas en C. VIDAL PRADO, El impacto del nuevo Derecho europeo en los Tribunales Constitucionales, Colex, Madrid, 2004, pp. 27 y ss. La reacción del TJ, en el asunto Nold, Sentencia del Tribunal de Justicia de las Comunidades Europeas de 14 de mayo de 1974, C-4/73, ECR 1974, pp. 00491 y ss.

${ }^{16}$ Ejemplos de este tipo de interpretación, en las Sentencias del Tribunal de Justicia de las Comunidades Europeas de 12 de diciembre de 1996, asuntos Procesos penales contra X, C-74-95 y 129-95, acumulados, ECR 1996, pp. I-06609 y ss., y Sentencia del Tribunal de Justicia de las Comunidades Europeas de 10 de febrero de 2000, asunto Deutsche Telekom $A G$ vs. Lili Schröder, C-50/96, ECR 2000, pp. I-00743 y ss. Son cuestiones prejudiciales en las que la primacía del Derecho comunitario, por decirlo así, cede sin ceder, ya que solo lo 
cuando las bases jurídicas que atribuyen competencias a la Unión le otorgan poderes conscientemente reducidos o acotados. La primacía y el pretexto de los fines de la integración consiguen que, incluso en casos de competencias complementarias, los límites que imponen los Tratados se desdibujen.

\subsection{La ordenación de las competencias de los Tratados}

A los problemas identificados en el plano de los valores constitucionales frente a los fines de la integración, se suma otro que es un clásico en los estudios sobre federalismo. Tiene su origen en la extremadamente dificultosa ordenación de sectores materiales de la realidad con el fin de establecer responsables exclusivos o conjuntos para su regulación. Lo que hacen las reglas de reparto de competencias en un orden federal es crear, a partir de la compartimentación de sectores de la realidad social, ámbitos materiales sobre los que los distintos entes -Federación, Estados- ejerzan sus poderes específicos.

A la dificultad de la propia segmentación jurídica de la realidad, se une la de la subsiguiente categorización de lo normativamente establecido. ¿Qué es una competencia exclusiva? ¿Qué es una competencia compartida y qué es lo que se comparte, la materia o las facultades que se ejercen sobre la materia? Cuando se comparte un sector material, ¿qué facultad prevalece, la de la Federación o la del Estado? En esta parte del discurso será útil tomar prestado un modelo teórico, una guía metodológica para el análisis. Nos apoyaremos en la forma en la que Ignacio de Otto explica este problema, cuando sostiene que en un sistema federal hay competencias plenas, compartidas, exclusivas y concurrentes ${ }^{17}$. Son plenas "cuando un sujeto, la Federación o los Estados, ostenta todas las facultades posibles sobre una materia». En este sentido, la competencia plena se opone a la compartida y se refiere al quantum de la atribución. Hay competencias exclusivas y concurrentes, por otro lado, que se diferencian entre ellas en el modo de la atribución. La exclusividad se predicaría de los casos en los que «la facultad de que se trate -sea cual sea su extensión - se atribuye de modo tal que el otro sujeto quede excluido de ella. La competencia es exclusiva porque el otro sujeto está excluido de ella -aunque pueda ostentar otra facultad sobre la materia, que sería compartida-». Las competencias concurrentes, sobre materias compartidas, se darían cuando «la atribución de una facultad a un sujeto no implica monopolio, exclusión del otro, sino que este dispone de la misma facultad, por ejemplo de la legislación o de la totalidad de las facultades de que dis-

hace en virtud de la inclusión en los Tratados de principios generales que son comunes a las tradiciones constitucionales de los Estados miembros.

${ }^{17}$ I. De OTTO y PARdo, Estudios sobre Derecho estatal y autonómico, Civitas, Madrid, 1986, pp. 58 y 59. Ahí se encuentran las citas textuales que siguen en el texto. 
pone el otro en la misma materia». Sería este último tipo de competencias concurrentes, o acumulativas, el que podría dar lugar a colisiones y requerir criterios de resolución. La prevalencia federal, que desplazaría las normas estatales a favor de las federales, sería una de las posibilidades de distensión del conflicto interordinamental ${ }^{18}$.

Si se descienden estos conceptos al caso europeo se ve que es difícil encontrar competencias-materias atribuidas plenamente en el repertorio mixto de objetivos y atribuciones. Solo con mirar la gran proporción de regulaciones comunitarias que deben ser ejecutadas por los Estados miembros, la afirmación de la plenitud de tal o cual competencia siempre quedaría en duda $^{19}$. Si se enfoca el análisis sobre ámbitos que solo legislan ya las autoridades europeas a través de Reglamentos, sería menos objetable identificar rasgos de plenitud material. Podrían ser los casos de la regulación aduanera o de la monetaria. Casos que son excepciones y que no impiden que haya normas estatales que, desde otro sector material, puedan entrar en conflicto con las europeas.

Lo cierto es que la mayor parte de las materias sobre las que la Unión tiene competencia son compartidas ${ }^{20}$. Incluso en casos en los que hay políticas lógicamente europeas -como la agrícola común-, su ámbito material -la agricultura- sigue estando compartido con los entes estatales, y con los regionales o subestatales cuando hay Estados miembros de estructura político-territorial. Tal y como se comparten estos ámbitos materiales, tampoco es sencillo identificar qué es exclusivo: si las facultades sobre materias o los objetivos de la atribución. Ello se pone de manifiesto en el breve listado de competencias exclusivas que el Tratado de Lisboa ha retomado del de la Constitución Europea -artículo 3 del TFUE-.

El resultado, en cuanto a facultades de producción normativa, ofrece un conjunto de ámbitos materiales compartidos sobre los que tanto la Unión

${ }^{18}$ I. De OTTO y PARDo, Estudios sobre..., op. cit. La prevalencia no sería necesaria en los casos de competencia plena de la Federación, pues los miembros no tendrían posibilidad de actuar sobre esa materia. Y tampoco en los casos de competencia exclusiva de la Federación, ya que los miembros no tienen poderes de actuación concurrentes.

${ }^{19}$ La Unión se concebiría, así, como un sistema federal de carácter administrativo, como opuesto al modelo de federación legislativa en la que el mismo ente ejecuta su propia legislación. W. SWENDEN, «Is the European Union in need of a competence catalogue? Insights from comparative federalism», Journal of Common Market Studies, vol. 42, 2004, pp. 371392, en concreto p. 381. La profesora MANGAS MARTín explica que «aunque los Tratados han confiado poderes de ejecución del Derecho Comunitario a las Instituciones (Consejo y Comisión), los Tratados también han reservado a los Estados miembros una parte importante de la ejecución del Derecho Comunitario». A. Mangas MarTín y D. LiÑán Nogueras, Instituciones y Derecho de la Unión Europea, Tecnos, Madrid, 2002, p. 485.

${ }^{20}$ Para Martín y Pérez de Nanclares hay una presunción de que las competencias comunitarias son compartidas. J. MARTín y PÉREZ DE NANCLARES, El sistema de competencias de la Comunidad Europea, McGrawHill, Madrid, 1997, p. 156. 
como los Estados tienen competencias, la mayoría concurrentes. La cuestión es que hay competencias concurrentes cuya modulación sugiere una preferencia por las regulaciones que se gesten en la esfera de la Unión. Pero hay otras en las que tal preferencia no solo no está tan clara, sino que se describen abiertamente como competencias estatales en las que la incidencia de la actuación europea debe ser, si lo es, secundaria. Se trata de las competencias complementarias, adscritas a la lógica de la subsidiariedad, pero acechadas por la de la primacía.

Llegados a este punto, estamos preparados para entrar en la cuestión de la interpretación de esas competencias concurrentes que son de complemento, apoyo o suplemento. Es en esa zona intermedia de los conflictos entre regulaciones europeas y estatales donde teóricamente funcionan esos dos principios mencionados: primacía y subsidiariedad. En la realidad de la interpretación última del Tribunal de Justicia, solo la primacía sirve para determinar el sentido de la preferencia por la competencia. La subsidiariedad, que sería el segundo principio, debería funcionar como refuerzo en la lectura federal de las competencias complementarias, pero de hecho no lo hace. Como consecuencia, los problemas derivados de la diversidad de parámetros de constitucionalidad y de la difícil segmentación de ámbitos de competencia son retroalimentados por la ausencia de una conveniente interpretación federal. Veámoslo.

\section{Las competencias complementarias y su interpretación}

La primera premisa sobre cualquier competencia de la Unión es que su sede normativa son los Tratados. Para el núcleo duro de la integración esa sede es el TCE, a partir de Lisboa será el TFUE. Son sus disposiciones las que dan detalle de los ámbitos de competencia que se atribuyen a la esfera supranacional: sus contenidos, límites, las facultades de regulación que se reconocen para su ejercicio, los objetivos que deben guiarlas y las exclusiones expresas de posibilidades de acción. En este sentido, y como principio, no habría objeciones a la afirmación de Dashwood de que «los límites de la autorización son discernibles con un tolerable grado de certidumbre» ${ }^{21}$. Pero a esta afirmación, justo a continuación en el discurso del mismo autor, le sigue otra. Esa segunda propuesta teórica sostiene que la efectividad de los límites depende del juego limpio de los actores institucionales, intérpretes políticos y jurídicos de las cláusulas de atribución. Y es esa afirmación la que

${ }^{21}$ La cita sigue: «... aunque si los límites son efectivos depende del juego limpio de las instituciones -y de que los Estados miembros no consientan el juego sucio». A. DASHWOOD, «The limits of European Community powers», European Law Review, vol. 21, 1996, pp. 113-128, en concreto p. 114. Las traducciones de las citas sacadas de trabajos en inglés y francés que se incluyen en este artículo han sido realizadas por su autora. 
aquí discutimos: ¿cómo se juega limpio cuando las reglas, en parte, orientan la acción de los partícipes a un uso abierto del encaje de las fichas? Los límites discernibles de las competencias atribuidas son puestos en solfa por ese finalismo abierto, que los revoluciona porque los impulsa a ir más allá de sí mismos. Además, el texto de los Tratados remite a la subsidiariedad y a su interpretación por los mismos actores institucionales europeos la deducción y toma en consideración de los espacios de actuación propiamente estatales. Es poco realista adherirse a la teoría del juego limpio con todos los jugadores en el mismo equipo. No lo es en ámbitos compartidos decantadamente europeos, como el mercado interior, pero tampoco en los ámbitos decantadamente estatales de competencias complementarias.

\subsection{Identificación y caracterización de las competencias complementarias}

En el proceso de crecimiento, paso a paso, de la Tercera Parte del TCE hay una fase amplia, que arranca con el Acta Única, en la que las atribuciones dejan de ser tan señaladamente económicas y empiezan a tocar otros terrenos, otras políticas ${ }^{22}$. Pero es la reforma de Maastricht la que señala el punto de inflexión a partir del cual la ampliación competencial adquiere connotaciones políticas independientes de lo económico ${ }^{23}$. Además de los pi-

\footnotetext{
${ }^{22}$ Como señala AldeCOA LuZÁRrAGA, «todas las reformas de los Tratados, aunque la de Niza en menor medida, han determinado un salto cualitativo en la cesión de competencias que van a ser ejercidas por la Unión. En efecto, se pasa de una Comunidad que, sustancialmente, ejercía cuatro políticas comunes de tipo sectorial o económico, cuales eran la agrícola, la de transportes, la comercial y la de competencia, a una Unión capaz de concebir y gestionar políticas no solo económicas sino de sociedad y, en los últimos tiempos, hacer incluso alta política» (F. ALDECOA LuZÁRRAGA, La integración europea. Análisis históricoinstitucional con textos y documentos, vol II. Génesis y desarrollo de la Unión Europea (1979-2002), Tecnos, Madrid, 2002, p. 51).

${ }^{23}$ El Acta Única Europea de 1987 introduce un nuevo objetivo para la CEE: el mercado interior. De cara a su instauración, el AUE atribuye a la CEE una serie de competencias, complementarias del mercado interior, que abarcan materias tales como capacidad monetaria, política social, cohesión económica y social, investigación y desarrollo tecnológico y medio ambiente. F. AldeCOA LuZÁrRAGA, La integración europea..., op. cit., pp. 106-107. Cinco años después, Maastricht se dirige hacia las metas de la unión económica y, aunque más prudentemente, de la política. Por una parte, mediante los nuevos pilares de cooperación intergubernamental -Política Exterior y de Seguridad Común y la original cooperación en asuntos de Justicia e Interior, actual Cooperación Policial y Judicial en Materia Penal-; por otra, mediante un considerable incremento de ámbitos de incidencia de la acción comunitaria. Dehousse las enumera: «ciudadanía europea, política de visados, educación, cultura, salud pública, protección a los consumidores, creación de redes de transporte transeuropeas, infraestructuras de telecomunicaciones y energía, industria y cooperación al desarrollo». R. DeHousse, «Community competences: are there limits to Growth?» en R. DEHOUSSE (ed.), Europe After Maastricht, An Ever Closer Union?, Law Books in Europe, Munich, 1994, pp. 103-125, en concreto p. 104.
} 
lares de cooperación intergubernamental en Política Exterior e Interior, origen de la estructura tripartita de la Unión, la propia Comunidad Europea recibe a través del Tratado de Maastricht un grupo de competencias nuevas en cuya definición se establece, expresamente, que se trata de ámbitos de acción complementaria a la estatal. Podemos identificar las que recogen los artículos 149 a 152 del TCE: por un lado educación y formación profesional dentro de la política social de la Comunidad, por otro cultura y salud pública. También, con matices, identificaremos la competencia sobre industria -157 TCE-.

Verbos como apoyar y complementar referidos a la acción de los Estados miembros caracterizan, y delimitan, esas cláusulas de atribución. A esas reglas sobre marcos de actuación, se suman restricciones textuales expresas a las posibilidades de actuación de las instituciones, que se concretan en la exclusión de toda armonización de las disposiciones legales y reglamentarias de los Estados miembros. Con ámbito de actuación algo mayor, aunque también dentro de una línea de complemento a la acción estatal, la política de industria no excluye la posibilidad de armonización, a pesar de lo cual se incluye como política de apoyo en la clasificación que hace el artículo 6 TFUE. Y es que en las últimas propuestas de reforma de los fundamentos del sistema jurídico comunitario -el Tratado constitucional y el de Lisboase han clasificado expresamente las mencionadas competencias como complementarias. El Tratado de Funcionamiento de la Unión separa estas competencias dentro de una categoría específica de apoyo, coordinación y complemento. La categoría se diferencia expresamente de las compartidas. Especifica que en ningún caso el ejercicio de la competencia comunitaria podrá suponer la sustitución de la competencia estatal -artículo 2.5 TFUE-. Esta precisión es esencial, no solo porque supone una afirmación de la prioridad de la competencia estatal, sino porque excluye la regla de preclusión que establece el párrafo 2 de ese mismo artículo -2 TFUE- para las competencias compartidas.

A ese repertorio ya conocido, que recoge el artículo 6 TFUE -cultura, salud, educación y formación profesional e industria-, se han añadido algunas materias de complemento más. En concreto, son nuevas políticas ya anunciadas y esperadas desde Niza sobre protección civil, turismo, deporte

\footnotetext{
${ }^{24}$ Ver los artículos III-281 y siguientes del Tratado que establece una Constitución para Europa, recogidos ahora por el Tratado de Lisboa en el Tratado de Funcionamiento de la Unión en los Títulos XII -deporte va junto con educación y formación profesional- y XXII a XIV -turismo, protección civil y cooperación administrativa-. Sin embargo, la protección a los consumidores, que en ciertas clasificaciones se había encontrado entre las consideradas de apoyo, es en Lisboa competencia compartida. Es lógico, puesto que la protección de los consumidores en el artículo 153 TCE es presentada como complementaria para el mercado interior, no como complementaria de la acción estatal. De hecho, en su cláusula de atribución no hay exclusión de la posibilidad de armonizar.
} 
y cooperación administrativa ${ }^{24}$. Como las anteriores, estas nuevas competencias complementarias excluyen las facultades de armonización y se ponen en un segundo plano respecto a las políticas estatales en dichos ámbitos. Un caso singular cierra la descripción. Hay una competencia de investigación y desarrollo tecnológico a la cual se le da una sede especial e intermedia: un párrafo aparte y exclusivo del artículo 4 del TFUE, dedicado a las competencias compartidas. En ese 4.3 del TFUE expresamente se excluye la preclusión de la competencia estatal en materia de investigación y desarrollo, lo cual la asimilaría a las complementarias si no fuera porque no le afecta la prohibición de armonización.

Algunas precisiones también son necesarias en relación con la competencia sobre salud pública. Es considerada como política de complemento en el artículo 6 TFUE, pero el artículo 4.2 TFUE dice en su apartado $k$ que los asuntos comunes de seguridad en materia de salud pública son competencia compartida. Es cierto que la ambigüedad en la definición de esta cuestión, la salud, como objeto de regulación europea está presente en las propias cláusulas de atribución del TCE. El artículo 152 contemplaba ya ciertos campos de la materia en los que la armonización no se excluye -152.4 $a$ y $b$ TCE-, pero otros en los que sí -152.4.c-. Luego, las propias cláusulas relativas al mercado interior en ocasiones consideran la salud como ámbito de excepción que, en ese sentido, sí eran susceptibles de quedar afectadas por regulaciones comunitarias. Según la base jurídica a la que se adhiriera el legislador europeo en su ejercicio competencial podría armonizar o no. El mismo artículo 95.3 TCE abre la posibilidad de armonizar legislaciones estatales en materia de salud, siempre que tal acción esté al servicio de la realización del mercado interior ${ }^{25}$.

Estructurando ideas previas al análisis de la interpretación, en primer lugar podríamos decir que este conjunto de competencias complementarias serían facultades de actuación otorgadas a la Comunidad sobre ámbitos materiales compartidos. Por supuesto, al no ser exclusivas ni de la Unión ni de los Estados, el ejercicio de estas competencias estaría prefigurado en un espacio de concurrencia marcado por una relación de complemento según la cual el principal responsable de estas políticas seguiría siendo el Estado miembro correspondiente. La Unión adoptaría una función secundaria en la regulación de estas materias. En segundo lugar, como ya hemos adelantado, se estaría hablando de un tipo de competencias especialmente representativas del concepto de subsidiariedad. Un concepto de subsidiariedad horizontal según el cual la identificación de la instancia óptima para ejercer el poder en un determinado sector material vendría dada por la combinación de los

${ }^{25}$ Ese mismo artículo se traslada al 114.3 del TFUE. Sobre el uso de bases jurídicas y su repercusión en las exclusiones de armonización, T. DE LA QUADRA-SALCEDO JANINI, El sistema europeo de distribución de competencias, Civitas, Madrid, 2006, pp. 116 y ss. 
elementos de «autodeterminación al nivel (...) más bajo posible y de subsidio del nivel superior al inferior» ${ }^{26}$. Incluso, y en tercer término, se trataría de facultades sobre materias que confirmarían la vigencia de la subsidiariedad como criterio operativo y modulador en el momento prenormativo o constitutivo -por no usar el término constituyente- de la atribución competencial ${ }^{27}$. La realidad es que se atribuyen a la Comunidad facultades de actuación para que sean ejercidas en la medida en que los Estados no logren alcanzar determinados objetivos relacionados con esos ámbitos de competencia, bien por la necesidad de medidas de carácter global, bien por la insuficiencia de la simple acción estatal ${ }^{28}$.

Esta presentación de las competencias complementarias nos pone por fin frente a la problemática de su interpretación. Un correcto entendimiento de estas normas de competencia ha de partir de su doble fundamento constitucional: las Constituciones y los Tratados. ¿Cuál sería la solución constitucional a un conflicto interpretativo entre dos normas, una estatal y otra europea, en alguno de esos ámbitos? ¿Habría que interpretar conforme a los objetivos del legislador estatal o conforme a los objetivos y dictados del europeo? ¿Sería adecuado modular la interpretación funcionalista habitual en el ejercicio de competencias comunitarias? ¿Cabría abrir paso a una interpretación federal que pusiera por delante los propios límites de las atribuciones o los fines prioritarios de las políticas estatales?

${ }^{26}$ F. Fonseca Morillo, «Legitimidad democrática: el principio de subsidiariedad», Europa Junta, núm. 11, diciembre 1992, pp. 5-23. En concreto, p. 7.

${ }^{27}$ Siendo cierto que la norma de la subsidiariedad (art. 5 TCE) solo se refiere al ejercicio de las competencias, también es evidente que la subsidiariedad tiene en la integración europea una función previa. Para Alicia Chicharro se trata de la función de presidir «especialmente los procesos constituyentes, es decir, a la hora del primer reparto de competencias y en sus sucesivas reformas», A. CHICHARRO LÁZARO, El principio de subsidiariedad en la Unión Europea, Aranzadi, Cizur Menor, 2001, p. 37. Lenaerts y Van Ypersele hablan de dos funciones del principio de subsidiariedad: la constitucional, de presidir el reparto de competencias, y la normativa, de regular el ejercicio de poderes. K. LENAERTS y P. VAN YPERSELE, «Le principe de subsidiarité et son contexte: étude de l'article 3B du Traité CE», Cahiers de Droit Européen, vol. 30, núms. 1-2, 1994, pp. 9-10. Del mismo modo, Gerkrath: «el principio de subsidiariedad ejerce en consecuencia una doble función en el ordenamiento jurídico comunitario. Interviene en tanto que principio rector de la atribución de competencias y ordena el ejercicio de competencias en los dominios en los que la competencia es compartida entre la Comunidad y sus Estados miembros. J. GERKRATH, L'emergence d'un droit constitutionnel pour l'Europe, Université de Bruxelles, Bruselas, 1997, p. 372.

${ }^{28}$ La subsidiariedad opera, según el artículo 5 TCE, «en la medida en que los objetivos de la acción pretendida no puedan ser alcanzados de manera suficiente por los Estados miembros, y, por consiguiente, puedan lograrse mejor, debido a la dimensión o a los efectos de la acción contemplada, a nivel comunitario». El artículo 5.3 del TUE(L) añade a esa definición que la insuficiencia de la acción podrá ser identificada bien a escala estatal-central, bien a escala regional, bien local. 


\subsection{Modelo de interpretación funcionalista}

Si se toma al funcionalismo como principio motriz de la integración, si se entiende que los Tratados establecen objetivos que las instituciones europeas están llamadas a conseguir, y si se acepta que las atribuciones de competencia están efectuadas de cara a que tales objetivos puedan alcanzarse, entonces es lógico que las instituciones europeas a la hora de ejercer las competencias efectúen interpretaciones finalistas. Se motiven sus actos legislativos sobre la base de las premisas del funcionalismo ${ }^{29}$. El problema del funcionalismo como criterio o método de la interpretación es que no está capacitado para integrar otros objetivos para los actos comunitarios que no sean los de los Tratados. El intérprete, por tanto, puede ser coherente con su norma de referencia, el Tratado, pero no con el marco global en el que se inserta la legitimidad de su actuación. Por tanto, si el legislador comunitario como intérprete primario, o primero, de las competencias se guía por esa interpretación finalista, lo que hará será fundamentar sus actuaciones en objetivos y principios de dimensión comunitaria. Y lo que nunca hará será tener la referencia de sus propios límites en los ámbitos de actuación estatal.

\subsubsection{EFECTO EN LA INTERPRETACIÓN INSTITUCIONAL Y SUBSIDIARIEDAD}

Frente a esa actuación o tendencia del funcionalismo, la subsidiariedad podría considerarse el mandato que vincula desde los Tratados, como normas de cabecera, a los actores institucionales europeos. Llama al legislador a tener en cuenta las posibilidades de actuación estatal. Así lo recoge, desde Maastricht, el artículo 5 del Tratado CE, en relación con el ejercicio de toda competencia comunitaria no exclusiva. La reforma de Lisboa lo mantiene, en el artículo 5.3 del TUE(L), con la novedad de que pro futuro los parlamentos nacionales tendrán posibilidad de objetar a las motivaciones que sobre la

\footnotetext{
${ }^{29}$ Como ya hemos señalado, el funcionalismo se concibe desde la Ciencia Política como teoría de la integración, por lo que hablar de él como método de interpretación de normas no es del todo ortodoxo. Sin embargo, desde el momento en el que sirve para explicar la manera en la que las competencias comunitarias son comprendidas por los actores institucionales de la Unión, incluido el propio Tribunal de Justicia, podemos entender que hay una interpretación funcionalista de las normas de atribución. Sobre el funcionalismo en la Unión y su oposición al federalismo como método de integración, L. J. CONSTANTINESCO, «Federalisme-constitutionnalisme ou fonctionnalisme? (Refléxions sur la méthode de l'intégration européenne)», en AA.VV. Mélanges Fernand Dehousse, Vol. 2. La construction européenne, Nathan Labor, Bruselas, 1979, pp. 19-27. Ver también en C. Closa MonTERO, «E pur si muove: teorías sobre la integración europea», op. cit. p. 350, cómo este autor explica la manera en la que el federalismo, que es una teoría normativa, se desenvuelve, con sus limitaciones, como teoría de la integración.
} 
subsidiariedad se hagan en las propuestas legislativas europeas. Ese nuevo procedimiento de control de la subsidiariedad, la alerta temprana, afectará a una cuestión que es crucial a la hora de interpretar estas competencias complementarias: quién define los objetivos de la acción, si son los Estados los que conservan la facultad de dar sentido al ejercicio de las competencias en esos ámbitos o si, una vez ejercidas las competencias en la esfera europea, son los objetivos de tal ejercicio los que pasan a dominar la interpretación ${ }^{30}$.

A consecuencia del funcionalismo y de la identificación de los objetivos comunitarios como referentes únicos suministrados por el Tratado, el principio de subsidiariedad poco ha podido hacer hasta ahora para facilitar la defensa de los ámbitos de actuación estatal en materia de competencia complementaria. Bien es cierto que en el campo de lo que hemos llamado interpretación institucional, a la hora de realizar regulaciones comunitarias, los conflictos interpretativos no son muy llamativos. Al revisar las actuaciones comunitarias en esos ámbitos concebidos como complementarios desde los noventa hasta hoy, se constatan dos cosas. Una es que las regulaciones comunitarias con base jurídica principal en alguna de esas disposiciones sobre materias de apoyo y complemento no son muy abundantes. Otra constatación es que los tipos de actos jurídicos que adoptan las instituciones en estos ámbitos suelen ser bien Recomendaciones, que siguiendo el 249 TCE no son vinculantes, bien Decisiones, que sí son vinculantes pero que se dirigen a destinatarios específicos y carecen, por tanto, del carácter general de los actos típicamente legislativos. De hecho, con base en los 149-150 y 151 TCE -cultura y educación, y formación profesional-, solo encontramos Recomendaciones y Decisiones, por más que algunas de esas Decisiones sean acuerdos de la Comunidad con países terceros que, desde ese punto de vista, tienen como destinatarios todos los Estados integrados en la CE. Hasta

${ }^{30}$ El procedimiento se anuncia en el artículo 5.3 del TUE(L) y se rescata del Tratado constitucional en el Protocolo número 2 sobre la aplicación de los principios de subsidiariedad y proporcionalidad. La intervención de los parlamentos nacionales en el inicio del procedimiento legislativo se concreta en unos dictámenes motivados que pueden denunciar las vulneraciones del principio de subsidiariedad que detecten en las propuestas legislativas y que, según los casos, obligarán a reconsiderar las formulaciones realizadas en tales propuestas. Ver, J. MARTín y PÉREZ DE NANCLARES, «La nueva regulación del régimen de competencias en el Tratado de Lisboa: especial referencia al control del principio de subsidiariedad», en J. MARTín y PÉREZ DE NANCLARES (coord.), El Tratado de Lisboa. La salida de la crisis constitucional, pp. 273-294; o bien, F. Aldecon LuZÁrraga, M. GuineA Llorente, La Europa que viene: el Tratado de Lisboa, Marcial Pons, Madrid, 2008, en especial pp. 181 y ss. También, sobre la regulación en el Tratado constitucional, L. M. HinOJOSA MARTíNEZ, El reparto de competencias entre la Unión Europea y sus Estados miembros, Tirant lo Blanch, Valencia, 2006.

${ }^{31}$ La utilización de bases jurídicas puede analizarse a través de la base de datos del Observatorio Legislativo del Parlamento Europeo, a disposición del público en general en $<$ http://www.europarl.europa.eu/oeil/search.jsp>. 
2002 no se encuentran disposiciones comunitarias de carácter legislativo, si damos rango de tales solo a Directivas y Reglamentos, que tengan su referencia en el artículo 152 TCE, relativo a salud pública ${ }^{31}$.

Aun con esa contención que se trasluce en el precavido uso de las bases jurídicas, el funcionalismo está presente en la mayor parte de esos actos jurídicos. Más que complementar los ámbitos de actuación estatales en sí, crean ámbitos de actuación europea en esas materias. En especial, esto se nota en los actos relativos a educación y formación profesional, cuyas motivaciones, en los considerandos que hace el legislador europeo, aluden por lo general a los principios de libre circulación como inductores o justificadores de la adopción de los actos.

Pero esas cuestiones tan menores se convierten en pequeños conflictos. Saltan si rastreamos algunas de esas disposiciones legislativas comunitarias basadas propiamente en el $152 \mathrm{TCE}$. Al analizar la manera en la que el legislador las motiva, se constata que no es la idea de complemento a la acción estatal la que preside la intención del mismo. Al contrario: hay fines europeos vinculados a la confianza en los intercambios intracomunitarios que justifican la adopción, por ejemplo, de medidas relativas al tratamiento de la sangre donada ${ }^{32}$. La normativa europea se manifiesta comprometida con objetivos concretos definidos por las propias instituciones europeas sobre la base que le dan los Tratados. Son objetivos que al no poder ser alcanzados de manera suficiente por los Estados miembros, según el propio legislador europeo, cumplen los criterios de la subsidiariedad y deben ser impulsados desde la propia Comunidad. Con escuetas motivaciones como esta se atribuye a la regulación europea carácter prioritario. Y, como el único requisito que hasta ahora ha exigido el Tribunal de Justicia para dar por bueno el respeto al principio de subsidiariedad es esa mínima declaración de insuficiencia de medios estatales y prioridad de los fines comunitarios, no se duda. Los efec-

\footnotetext{
${ }^{32}$ A modo de ejemplo, señalamos los «considerandos» o motivaciones de las Directivas 2002/98/CE del Parlamento Europeo y del Consejo, de 27 de enero de 2003, por las que se establecen normas de calidad y de seguridad para la extracción, verificación, tratamiento, almacenamiento y distribución de sangre humana y sus componentes y por las que se modifica la Directiva 2001/83/CE, Diario Oficial de la Unión Europea, núm. L 033 de 08/02/2003, pp. 0030-0040; y 2004/23/CE del Parlamento Europeo y del Consejo, de 31 de marzo de 2004, relativa al establecimiento de normas de calidad y de seguridad para la donación, la obtención, la evaluación, el procesamiento, la preservación, el almacenamiento y la distribución de células y tejidos humanos, Diario Oficial de la Unión Europea, núm. L 102 de 07/04/2004 pp. 0048-0058. En el 152 TCE también se fundamenta el Reglamento 851/2004/CE del Parlamento Europeo y del Consejo, de 21 de abril de 2004, por el que se crea un Centro Europeo para la prevención y el control de las enfermedades, Diario Oficial de la Unión Europea, núm. L 142 de 30/04/2004, pp. 0001-0011.

${ }^{33}$ En efecto, hasta ahora el Tribunal de Justicia ha ido dando por buena cualquier justificación del respeto a la subsidiariedad que diera el legislador comunitario, incluso cuando la referencia expresa al principio del artículo 5 TCE no aparecía por ningún lado en la motiva-
} 
tos del funcionalismo sobre la comprensión de las competencias complementarias hacen que estas dejen de ser complemento alguno y pasen a ser, por sí mismas, instrumentos de integración ${ }^{33}$. Los efectos del funcionalismo sobre la subsidiariedad eliminan las objeciones que dicha norma pudiera oponer.

\subsubsection{EFECTO EN LA INTERPRETACIÓN JURISPRUDENCIAL Y SUBSIDIARIEDAD}

En postrer término, y en lo que a la jurisprudencia se refiere, destacaremos un asunto también relativo a la materia de salud pública. De la QuadraSalcedo Janini nos ilustra sobre la forma en la que el Tribunal de Justicia prioriza, en la comprensión de las normas comunitarias, los fines de la integración y no los límites que para las competencias complementarias fija el Tratado CE. Se trata de la sentencia de 5 de octubre de 2000, un recurso de anulación de Alemania contra la Directiva 98/43/CE sobre publicidad y patrocinio de productos del tabaco ${ }^{34}$. Entre otras cosas, Alemania sostiene en el desarrollo de las alegaciones que la base jurídica elegida por las instituciones europeas debía haber sido la complementaria de protección de la salud -actual 152 TCE-, en lugar del artículo que trata sobre la armonización de legislaciones estatales en materias tales como la salud para el mejor funcionamiento del mercado interior -antiguo 100A TCE, actual 95 TCE-.

Aunque el TJ acaba anulando la Directiva, lo cierto es que lo hace por otros motivos. Frente a la protesta alemana por el uso de las bases jurídicas, argumenta el juez comunitario que la protección de la salud es tratada en la Directiva como objetivo secundario de la propia armonización ${ }^{35}$. Esa posibilidad interpretativa, coherente con el funcionalismo que impregna el Dere-

ción del acto del que se tratase. Explican la forma en la que el TJ interpreta la exigencia de motivación de la subsidiariedad por el legislador E. AlberTí, E. Fossas y M. A. CABELlos en El principio de subsidiariedad en la Unión Europea: su consagración en el Tratado por el que se establece una Constitución para Europa y las perspectivas para las regiones con poderes legislativos y, en especial, para sus parlamentos, documento elaborado por el Instituto de Estudios Autonómicos a petición del Presidente del Parlamento de Cataluña, 14 de febrero de 2005, en <http://www.calre.eu/en/subsidiarity_en.html>, pp. 18 y ss. Las impugnaciones basadas en la subsidiariedad son ciertamente escasas y lo poco que responde el Tribunal de Justicia se aferra a esa mínima exigencia de motivación. A. EsTELla DE NoRIEGA, «La paradoja de la subsidiariedad: reflexiones en torno a la jurisprudencia comunitaria relativa al artículo 3B (2) del Tratado de la Comunidad Europea», Revista Española de Derecho Administrativo, núm. 101, 1999, pp. 71-100.

${ }^{34}$ Asunto Alemania vs. Consejo y Parlamento Europeo, Sentencia del Tribunal de Justicia de las Comunidades Europeas de 5 de octubre de 2000, C-376/98, ECR 2000, pp. I08419 y ss. Como decimos, este caso y su incidencia sobre las competencias complementarias es estudiado con detalle en T. DE LA QUADRA-SALCEDO JANINI, El sistema europeo de..., op. cit., pp. 116 y ss.

${ }^{35}$ Ver el fundamento 88 de la citada STJCE de 5 de octubre de 2000. 
cho derivado y con el juego de los artículos 95 TCE y 152 TCE, abre sin embargo tres interrogantes al análisis del ejercicio competencial. Uno es sobre la naturaleza complementaria de la competencia comunitaria «salud», pues si puede leerse como apoyo y complemento tanto de la esfera de competencia estatal como del mercado interior, ¿cuándo funciona en la primera de las dos lecturas? El segundo interrogante está relacionado con esa sistematización de valores, puesto que si el objetivo es la construcción del mercado interior y no la salud en sí, ¿los límites del 152 no vinculan en ningún caso? Como última incógnita, tercera, aparece la de la función de los mandatos del principio de subsidiariedad, pues su grado de relevancia debería ser mayor en una regulación sobre salud pública que en una regulación sobre mercado interior por la propia naturaleza de las atribuciones. Sin embargo, llegado el caso ¿qué otra cosa sino primacía se utilizaría para dilucidar un hipotético conflicto entre una norma estatal en materia de salud y una norma europea armonizadora del mercado interior?

\subsubsection{EFECTO EN LA INTERPRETACIÓN JURISPRUDENCIAL Y PRIMACÍA}

En continuidad con todo lo anterior, siguen las preguntas: ¿en qué queda, entonces, el ámbito de participación estatal en estas materias?, ¿es complementado o es él el que complementa? En efecto, la prioridad dada a los fines de la integración tiene como consecuencia que el Derecho comunitario se aplique en estos casos con preferencia al estatal en caso de conflicto. El criterio de resolución del conflicto normativo que pueda implicar materias objeto de competencias complementarias es la primacía, a pesar de que el principio informador de su naturaleza es el de subsidiariedad y de que la configuración de la atribución no respalda tal concepción ${ }^{36}$.

Para que la aplicación de la primacía sea lo más limpia posible, el juez comunitario necesita concebir la materia objeto de regulación como complementaria no del Derecho estatal, sino del comunitario. Esa inversión a la hora de enfrentarse a la materia atribuida es lo que hacía el Tribunal de Justicia en la resolución sobre la Directiva de la publicidad del tabaco, si bien en ese caso la discusión sobre bases jurídicas daba la cobertura al giro, a la prioridad de los fines comunitarios. Pero más llamativo resulta que la misma dinámica interpretativa se aplique en cuestiones prejudiciales cuando regulacio-

\footnotetext{
${ }^{36}$ HinOJOSA MARTíNEZ señala la primacía como norma de solución de conflictos que también vincula en ámbitos de competencia complementaria en L. M. HinOJOSA MARTíneZ, El reparto de competencias entre la Unión Europea..., op. cit., p. 102. La visión diferente, que reclama que la solución de este tipo de conflictos se haga a través del principio de atribución en vez de a través del de primacía, en T. DE LA QUADRA-SALCEDo JANINI, El sistema europeo de.., op. cit., p. 125.
} 
nes estatales en ámbitos de competencia propia se cruzan, sobre el terreno, con normas de los Tratados, o de Derecho derivado, que parten o avanzan en otra dirección.

Esta dinámica hermenéutica ya se detecta en sentencias anteriores a Maastricht. Es decir: anteriores a la consignación en los Tratados de las atribuciones de apoyo y complemento. Un ejemplo es el del caso Matteuсci ${ }^{37}$. Se trata de una sentencia del año 1988 en la que se resuelve el asunto que enfrentaba a una ciudadana italiana con el Estado belga. A Annunciata Matteucci se le deniega, en Bélgica, una beca de formación para Alemania. La concesión de estas becas, según un acuerdo cultural de 1956 entre Bélgica y Alemania, estaba reservada a los ciudadanos belgas y, como es deducible, se trataba de un acuerdo relacionado con ámbitos de cultura o educación, precisamente dos de los que en Maastricht se incluirían como complementarios en los Tratados. El asunto llega al TJ como cuestión prejudicial de interpretación y, en su resolución, el juez comunitario confronta los criterios para la concesión de las becas del acuerdo cultural, con dos fuentes normativas distintas. Una era la propia prohibición de discriminación por nacionalidad en el ámbito del Tratado, del artículo 7 TCE. Otra era lo dispuesto en el Reglamento CEE 1612/68, que obligaba a extender las ventajas sociales de los trabajadores de un Estado miembro dado a los de los demás Estados miembros.

El gobierno francés, personado en el proceso, llamó específicamente la atención acerca de la naturaleza cultural del acuerdo, ámbito al cual no eran aplicables las disposiciones del Tratado. No olvidemos ni que la sentencia es de 1988, ni que la prohibición de discriminación del artículo 7 TCE se refería al ámbito del Tratado. El Tribunal de Justicia, sin embargo, consideró que, mientras se tratase de ventajas para trabajadores, aplicaría el Tratado, por supuesto, con preeminencia. Lo único que concedía el juez comunitario al nacional es que fuera él mismo quien determinara si, en el caso concreto, la actividad de Matteucci se correspondía con el concepto de trabajador protegido por el Derecho comunitario. No importaba si el objeto del acuerdo entraba dentro del ámbito del Tratado, sino si el objetivo del Tratado se integraba en el acuerdo ${ }^{38}$. En consecuencia, la materia del acuerdo interestatal no vinculaba desde ningún parámetro de interpretación al juez comunitario.

Nos queda por saber qué pudo hacer el juez belga, en su día, con esa respuesta del Tribunal de Luxemburgo. Pero, en lo que a esta reflexión atañe,

${ }^{37}$ Asunto Matteucci, sentencia del Tribunal de Justicia de las Comunidades Europeas de 27 de septiembre de 1988, C-235/87, ECR 1988, pp. 05589 y ss.

${ }^{38}$ Ver el fundamento 9 de la citada STJCE de 27 de septiembre de 1988.

${ }^{39}$ Las reflexiones del Grupo de Trabajo sobre Competencias Complementarias de la Convención sobre el futuro de Europa, que trabajó en la propuesta del Tratado que Establece una Constitución para Europa, eran muy conscientes de esa comprensión de la idea de complemento tenía que ser corregida. De hecho se insistió en que las competencias comple- 
cabe preguntarse si la introducción en Maastricht de todas las disposiciones relativas a estas competencias de apoyo y complemento no trataba, precisamente, de evitar este tipo de interpretación ${ }^{39}$. Cabe preguntarse si realmente los límites que se impusieron a la Comunidad en estas materias pueden mantenerse indemnes si no se tiene en cuenta la competencia estatal como referente en la interpretación. La primacía no consigue ese efecto, puesto que también es un principio informado por los fines de la integración y no un principio federal. La interpretación conforme a la primacía y conforme a los fines del Tratado relega la materia complementaria a un lugar secundario, por lo que no queda sitio para hacer valer los límites de actuación que tiene la Comunidad. De esta forma, desde la visión del TJ, incluso para el legislador estatal los principios que deben inspirar la ordenación de tales materias dejan de ser los de la propia Constitución. El juez comunitario no entra a juzgar la validez de las normas estatales, pero condiciona su aplicación según los fines de la integración, los de los Tratados. Con este tipo de giros, una competencia regulación principalmente estatal se transforma en una competencia secundariamente europea. La última cuestión es: ¿habría un modelo de interpretación federal que pudiese dar un giro a esta dinámica interpretativa y devolver a las competencias complementarias su dimensión de tales?

\section{Condiciones o principios para una interpretación federal}

Hemos visto hasta ahora cómo se desenvuelven las competencias complementarias bajo la disciplina hermenéutica del funcionalismo y con la cobertura que le ofrecen los principios de primacía y subsidiariedad, impregnados también de ese sentido funcionalista. De lo que se trataría ahora, finalmente y como aportación desde la comprensión federal del fenómeno de la integración europea, es de ver si con un tratamiento distinto de esos dos principios de interrelación, sería posible transformar la interpretación funcionalista de las competencias complementarias en interpretación federal. De cualquier modo, está claro que los límites de la atribución no sirven por sí solos para contener las tendencias expansivas de la regulación de materias desde el orden europeo. Eso es algo común incluso en sistemas federales basados en la supremacía de una norma constitucional que establece un reparto de competencias. En la Unión, se suma el hecho de que los criterios utilizados en la interpretación tienen un efecto concreto sobre la conforma-

mentarias redujesen su «estatus» y se mencionasen solo como «medidas de apoyo». CONV 375/1/02, «Informe final del Grupo V sobre Competencias complementarias», de 31 de octubre de 2002. Los documentos de la convención pueden consultarse en castellano en $<$ http://european-convention.eu.int/bienvenue.asp?lang=ES>, Un resumen comentado, J. AlguACIL GONZÁLEZ-AuRIOLES, La elaboración del Tratado por el que se establece una Constitución para Europa, CEPC-BOE, Madrid, 2005. 
ción de las dinámicas efectivas de funcionamiento de las competencias: al solo contemplar los objetivos de los Tratados, invierten su naturaleza y pasan a ser complemento de las acciones de la propia Unión. Como resultado, los objetivos que motivan regulaciones estatales, legítimas según sus referentes constitucionales, son olvidados sin que haya posibilidad de que sean rescatados. Habría que empezar considerando si la subsidiariedad puede tener ahí alguna función distinta de la que viene cumpliendo.

El caso de la subsidiariedad es, en efecto, el de una norma de corte federal cuyos contenidos esenciales llaman al respeto de los espacios de actuación estatales siempre que sea posible. Pero si la interpretación de la subsidiariedad se hace sobre la base de su correspondencia con la competencia europea y con su objetivo, se bloquean sus posibilidades de actuación como norma de inclusión del respeto a los ámbitos de ejercicio estatal de las competencias. Sería conveniente que la norma pudiera ser más un principio de respeto de los ámbitos de competencia estatales que un mero justificante de la acción comunitaria. Concretamente, para las competencias complementarias debería ser un principio que orientase la interpretación institucional y de la jurisprudencia siempre a favor de la preferencia por el ejercicio estatal de la competencia ${ }^{40}$.

El camino para esa transformación podría desbloquearse con el mecanismo de alerta temprana, que espera a entrar en vigor a que el Tratado de Lisboa lo haga. Si los parlamentos nacionales y regionales pasan a aportar claves de interpretación de la competencia en juego, la interpretación de la subsidiariedad puede fortalecer su relación con la competencia y no depender tanto de su relación con la eficacia. Sea como sea, la inclusión de intérpretes estatales en la aplicación de la subsidiariedad es fundamental. La comprensión de los límites de la atribución complementaria desde el propio parámetro estatal obligaría a las instituciones europeas a ajustar mucho mejor sus propuestas legislativas. Sin embargo, la subsidiariedad seguiría teniendo en el ámbito jurisprudencial el mismo problema que viene acarreando desde su inclusión en los Tratados: que el Tribunal de Justicia no se atreve a exigir, para dar el visto bueno a su respeto, mucho más que un criterio formal de motivación. Reforzarse la exigencia de motivación, que deberá tener en cuenta las alegaciones que hagan los parlamentos de los Estados miembros, podría tener repercusiones también en la comprensión que el juez comuni-

${ }^{40}$ Sugiere Schilling que la subsidiariedad vista como principio noramativo puede servir de contrapeso a la primacía en ciertos casos de colisión normativa. T. ScHILLING, «Subsidiarity as a rule and a principle, or: taking subsidiarity seriously», Harvard Jean Monnet Working Paper 10/95, <http://www.jeanmonnetprogram.org/papers/95/9510ind.html>. Desde otra perspectiva, T. R. FERNÁNDEZ, «Sobre la necesaria elevación del rango de los principios de subsidiariedad y proporcionalidad», en E. GARCíA DE ENTERRía (dir.) y R. AlONSO GARCía (subdir.), La Encrucijada Constitucional de la Unión Europea, Civitas, Madrid, 2002, pp. 103-110. 
tario hace de la subsidiariedad. En especial cuando una norma estatal en ámbito de apoyo o complemento choque con una norma de Derecho derivado europeo orientada según una base jurídica diferente.

En el caso de la primacía, su transformación pasaría por adaptarla para que sus contenidos priorizasen los mandatos europeos en los casos en los que verdaderamente ese fuera el sentido de la atribución. La solución quizás no sea reducir la primacía a un problema de aplicabilidad para evitar controversias teóricas ${ }^{41}$. Cuando eso ocurre, la primacía se desviste de los contenidos federales que la ciñen a proteger la preferencia por el Derecho europeo en su ámbito de competencia. Si el fundamento del orden europeo es doble, Tratados y Constituciones, el de la primacía también está en dos $\operatorname{lados}^{42}$. Dicho de otra manera, la primacía como simple regla de desplazamiento no explica suficientemente las razones por las cuales una norma estatal válida es desplazada por otra comunitaria desde una comprensión pluriconstitucional y federal del sistema europeo. Si las normas estatales que entran en conflicto son disposiciones constitucionales hay que repensar la primacía ${ }^{43}$, igual que si se trata de ejercicio de competencias en las que la Unión solo tiene facultades de apoyo y complemento.

Aunque no sea realista aspirar a dar a los Tratados un tratamiento de Constitución federal, sí podría darse un contenido federal a la primacía, acotando su incidencia cuando estén presentes contenidos constitucionales y ámbitos de competencia estatal preferente. El riesgo de convertirla en indis-

${ }^{41}$ Es sabido que la primacía no desencadena un juicio sobre la validez-invalidez de las normas objeto de conflicto. Solo decide que la norma comunitaria válida se aplique, mientras la estatal, cuya validez no se prejuzga, se dejaría inaplicada. Así entiende la primacía J. L. Requejo Pagés, Sistemas normativos, Constitución y ordenamiento. La Constitución como norma sobre la aplicación de normas, McGrawHill, Madrid, 1995, p. 63. Sin embargo, en la actualidad, se discute que la primacía pueda, en una perspectiva multiconstitucional, reducirse a simple aplicabilidad o, en el otro extremo, a supremacía constitucional en sentido estricto. Ver el trabajo de A. Von BogdANDY, «Doctrine of principles», en European Integration: the new German scholarship, Jean Monnet Working Paper 9/03, <http://www.jeanmonnetprogram.org/papers/03/030901-01.html>, pp. 41 y 42.

${ }_{42}$ Mientras para el TJ la primacía del derecho comunitario se fundamenta en el propio orden comunitario, los jueces nacionales la basan por lo general en la Constitución propia Así lo explica, entre otros B. De Witte, para quien, la primacía sigue siendo, en parte, Derecho internacional. B. DE WITTE, «Direct effect, supremacy, and the nature of legal order», P. Craig y G. De Búrca (eds.), The Evolution of EU Law, Oxford University Press, Oxford, 1999, pp. 177-213, en concreto p. 209.

${ }^{43}$ M. Kumm y V. FerReres Comellas, «The future of constitutional conflict in the European Union: constitutional supremacy after the constitutional treaty», en J. H. H. WEILER and C. L. EISBURGER, (eds.), Altneuland: The EU Constitution in a contextual perspective, Jean Monnet Working Paper 5/04, <http://www.jeanmonnetprogram.org/papers/04/ 040501-15.html>. 
cutible se compensaría al interpretarla en coherencia con otros principios que aportasen contenidos de contrapeso. El respeto a la identidad nacional de los Estados miembros -6.3 TUE(N), 4.2 TUE(L) - daría entrada a la condición de respeto a los ámbitos de competencia estatales ${ }^{44}$. La subsidiariedad los preservaría cuando el ejercicio comunitario de la competencia no estuviese suficientemente justificado.

\section{Conclusión}

Hay que reconsiderar los referentes que guían la interpretación constitucional de las competencias complementarias si se desea que estas se ajusten mejor a los límites de las atribuciones. Mientras la interpretación institucional y jurisprudencial solo se fundamente en los fines de la integración, la existencia de categorizaciones de competencias y límites normativos a su ejercicio siempre puede ser esquivada. Pero suministrar referentes para la interpretación acordes con la concepción pluralista del orden constitucional europeo no puede ser solo una labor del legislador o del juez comunitario. Es en gran parte una tarea constituyente y normativa.

Por un lado, sería necesaria una redefinición de la primacía, algo más valiente y más acorde con la pretensión de interrelación no jerárquica que preside la comprensión del pluralismo constitucional europeo. La reforma de Lisboa ha perdido la ocasión de hacerlo al eliminar el artículo I-6 que incluía el Tratado constitucional. El discorde fundamento de la primacía según lo expliquen órganos jurisdiccionales estatales y europeos solo puede armonizarse suministrando a dichos actores un principio de primacía claro. La verosimilitud constitucional del complejo europeo exige una coordinación de valores normativos. Por otro lado, también sería preciso un tratamiento algo más incisivo del respeto de la subsidiariedad, en especial cuando esas competencias sean primordialmente estatales y secundariamente europeas. La ocasión para hacer una construcción de contenidos de la subsidiariedad,

\footnotetext{
${ }^{44}$ Sobre el tratamiento de la identidad nacional y su relación con la distribución competencial, centrado en el análisis del proyecto de la Convención del Tratado constitucional europeo, López Castillo: «sin ser exactamente una de esas cláusulas de atribución "impropia", o de "delimitación" del alcance de la atribución, tanto por su generalidad como por su textura principal, deja abierta una vía de integración negativa del alcance de las competencias atribuidas a la Unión que, a la manera de una compleja "Constitución territorial", quedarían delimitadas de forma refleja, a partir del negativo de una "identidad nacional" acerca de la que, en último término, vendría a decidir el intérprete supremo del ordenamiento integrado en cuestión. Sin necesidad de apurar aquí las consecuencias de esta imbricación, es justo dejar indicada la dificultad de pacífica integración de una cláusula tan abierta si no es mediante algún tipo de prejudicialidad inversa». A. LóPEZ CASTILLO, «Acerca de la delimitación de competencias en el proyecto constitucional de la UE», Revisa de Derecho Comunitario Europeo, núm. 18, 2004, pp. 433-462, en concreto, pp. 451 y 452.
} 
como principio federal, que proteja el ejercicio de competencias de Estados y entes regionales puede llegar con la puesta en marcha del mecanismo de alerta temprana.

El equilibrio metaconstitucional ${ }^{45}$ en la interrelación entre orden constitucional europeo y órdenes estatales depende de que las exigencias recíprocas de respeto a cada uno de ellos se incorporen en Tratados y Constituciones. De esta forma, cada uno de los intérpretes podrá encontrar en su propio parámetro las pautas necesarias para dar a los conflictos soluciones acordes con la comprensión global del conjunto. Los principios de primacía y subsidiariedad son bisagras óptimas, si se las encaja bien. Al fin y al cabo, el federalismo en la Unión, con sus peculiaridades, podría ganar la partida, el Tetris de las competencias, versión post-Lisboa.

${ }^{45}$ P. Cruz Villalón, La Constitución inédita..., op. cit., p. 139. 